\title{
La regulación de precios en el mercado de combustibles en Argentina (1989-2015): del libre mercado a una estructura oligopólica
}

\author{
Mariano Barrera*
}

Fecha de recepción: 7 de marzo de 2019

Fecha de aprobación: 30 de julio de 2019

Resumen: La crisis económica de finales de la década de 1980 implicó un cambio estructural en la economía argentina, del cual el complejo hidrocarburífero no estuvo exento. En este marco, el objetivo del artículo es analizar cuáles fueron las propuestas de reforma neoliberales, cómo fue su implementación y cuál fue el impacto en la dinámica del mercado de combustibles, considerando su morfología, la dinámica de los precios y las cantidades producidas, tanto durante los años noventa como luego de la crisis de la convertibilidad y el inicio de un nuevo proceso en el complejo hidrocarburífero con regulación de precios. Para ello, el estudio contempla el uso de técnicas de recolección y análisis cualitativas, que permiten relevar y analizar las declaraciones de los principales actores tanto políticos como económicos, así como técnicas cuantitativas a través del procesamiento de estadísticas oficiales tanto nacionales como internacionales.

Palabras clave: combustibles, Argentina, oligopolio, privatización, regulación.

Clasificación JEL: L71, L51, L33, N56, O14.

Cómo citar este artículo/ To reference this article / Comment citer cet article / Para citar este artigo:

Barrera, M. (2020). La regulación de precios en el mercado de combustibles en Argentina (1989-2015): del libre mercado a una estructura oligopólica. Apuntes del Cenes, 39(69). Págs. 103 - 133 https://doi.org/10.19053/01203053. v39.n69.2020.9019

\footnotetext{
* Doctor en Ciencias Sociales. Investigador del Consejo Nacional de Investigaciones Científicas y Técnicas (CONICET) y del Área de Economía y Tecnología de la FLACSO. Argentina. Correo electrónico: mbarrera@flacso.org.ar. Q http://orcid.org/0000-0003-3303-439X
} 


\title{
Prices Regulation in the Fuel Market in Argentina (1989-2015): From the Free Market to an Oligopolistic Structure
}

\begin{abstract}
The economic crisis of the late 1980s implied a structural change in the Argentine economy of which the hydrocarbon complex was not exempt. In this framework, the objective of the article is to analyze what the neoliberal reform proposals were, how they were implemented and what was the impact on the dynamics of the fuel market considering its morphology, the price dynamics and the quantities produced, both during the nineties as after the crisis of the convertibility and the beginning of a new process in the hydrocarbon complex with price regulation. For this, the study contemplates the use of qualitative collection and analysis techniques that allow to survey and analyze the declarations of the main political and economic actors, as well as quantitative techniques through the processing of official national and international statistics.
\end{abstract}

Keywords: fuels, Argentina, oligopoly, privatization, regulation. 


\section{INTRODUCCIÓN}

Históricamente, el complejo hidrocarburífero en Argentina estuvo controlado por la compañía estatal Yacimientos Petroliferos Fiscales (YPF) desde que en 1929, siete años después de su creación como empresa, logró fijar el precio de los combustibles líquidos comercializados internamente. Hasta la década de 1990, con sus más y sus menos, el precio de los bienes energéticos estuvo desvinculado de los valores internacionales, ya que el peso de la compañía en la producción de hidrocarburos (extraía de forma directa el 65\% del petróleo local, y a través de contratistas, el $33 \%$ ), en la refinación (70\%) y en la comercialización $(63 \%)$, le permitía al Estado establecer una política interna, amparado en una batería normativa que con los años le fue dando mayor poder de regulación a la Secretaría de Energía.

Esta arquitectura institucional sectorial, característica del modelo de regulación pública con predominio de la empresa estatal (Barrera, 2014), en la que el petróleo extraído era distribuido por la "mesa de crudos" a las diversas refinerías existentes a partir de las cuotas establecidas en función de los criterios allí fijados, fue desarticulada con las reformas implementadas por el Gobierno de Carlos Menem a partir de 1989 (Barrera, 2014; Gerchunoff, 1994; Kozulj \& Bravo, 1993; Montamat, 1995). Se puso en marcha un modelo privatista en el que en apenas cinco años se vendieron y se otorgaron concesiones a algo más de treinta empresas estatales nacionales de múltiples sectores, por medio de los cuales el Estado recaudó, hasta 1999, 23849 millones de dólares (Azpiazu, 2003; Gerchunoff \& Cánovas, 1995; MECON, 2001b).

En este sentido, el objetivo central del artículo es analizar cómo operó el mercado de refinación de petróleo y ventas de combustibles (downstream) en Argentina, luego de las reformas de mercado implementadas en la década de 1990, que configuraron un mercado oligopólico privado, y cuál fue la dinámica después de 2002 cuando los sucesivos gobiernos aplicaron medidas de controles de precios sobre la misma estructura oligopólica. Se trata de un campo escasamente estudiado por la li- 
teratura del sector energético en el país. La hipótesis central del trabajo es que en la década de 1990 las firmas privadas pudieron capturar renta oligopólica por la posición dominante, pese a las desregulaciones, y que entre 2002 y 2015, los controles de precios derivaron en que las firmas restringieran las cantidades producidas para forzar la convergencia con el precio de paridad de importación. Para ello, se dividirá el período en dos etapas: la primera, que comprende los años 1989-2001, en los que luego de la privatización de la petrolera estatal y la desregulación del complejo energético, las empresas operaron con plena libertad de mercado tanto en la asignación de cantidades como de precios, a partir de la convergencia con los valores internacionales. La segunda, comprendida entre los años 2002-2015, que se inició con la ruptura del modelo de convertibilidad y que finalizó con el triunfo en las elecciones presidenciales de Mauricio Macri, en la que, en una primera etapa, se aplicaron políticas que desvincularon los precios domésticos por debajo de los externos y que, hacia el final del período y luego de la expropiación del $51 \%$ de la petrolera estatal, la cotización interna superó la internacional como un mecanismo de fomento a las inversiones. En suma, se trata de analizar el impacto de cada una de las políticas, en su contexto histórico y a partir de las declaraciones de los principales actores, en el marco del análisis estructural del mercado.

\section{LOS CAMBIOS ESTRUCTURALES Y EL CONTEXTO HISTÓRICO}

El Gobierno de Carlos Menem comenzó crisis económica y política, que desencadenó una reestructuración de la forma de intervención del Estado en la sociedad. En el marco del Consenso de Washington ${ }^{1}$, se iniciaron los procesos de privatización de empresas y de desregulación de los mercados, además de la suspensión de los subsidios, subvenciones, reembolsos y reintegros tributarios otorgados al capital durante las décadas previas (Azpiazu, 2003; Pucciarelli, 2011). Al mismo tiempo, se expidieron tres decretos que implementaron el proceso de desregulación de la actividad hidrocarburífera. Se trata de los decretos 1055,1212 y 1589 , todos de 1989 , que fueron extinguiendo capacidades estatales. Las normas eliminaron la "mesa de crudo", liberaron los precios y otorgaron la libre disponibilidad de los hidrocarburos extraídos a las firmas privadas, las cuales podían empezar a importar y exportar sin restricciones y disponer libremente de hasta el $70 \%$ de las divisas generadas por el comercio. En los considerandos de las normas se establecía que el objetivo era fijar

1 Se utilizó para articular una serie de políticas que pregonaban los organismos internacionales, con el apoyo de Estados Unidos, hacia América Latina, que consistían en: mantener una férrea disciplina fiscal; reorientar las prioridades del gasto público hacia campos que ofrecieran un alto rendimiento económico y un potencial de mejora tanto en la distribución del ingreso, como en la atención primaria de la salud, la educación primaria y la infraestructura, en detrimento de las empresas públicas; implementar una reforma tributaria; liberalizar los tipos de interés y de cambio; quitar restricciones al comercio; y librar la cuenta capital y financiera; privatizar empresas públicas; desregular la economía y garantizar los derechos de propiedad (Williamson, 1990). 
"reglas que privilegian los mecanismos de mercado para la fijación de precios, asignación de cantidades valores de transferencia y/o bonificaciones en las distintas etapas de la actividad" (Decreto 1212 de 1989) con la finalidad de que esta desregulación "conduzca a la efectiva y libre competencia en todos los segmentos en el menor tiempo posible reflejando los valores internacionales" (Decreto 1055 de 1989) ${ }^{2}$ (Azpiazu \& Schorr, 2001; Barrera, 2012, 2014; FIEL, 1999; Gerchunoff \& Cánovas, 1995; Kozulj, 2002; Kozulj \& Bravo, 1993; Sabbatella, 2014; Serrani, 2011).

El cambio en los precios de los bienes energéticos en Argentina significó el paso de un esquema de precios regulados por el Estado a partir de variables locales (como el índice de precios mayoristas) a la liberación y dolarización, para que convergieran con las cotizaciones internacionales. La razón detrás de estas medidas era que al ser los hidrocarburos una mercancía como cualquier otra, con la anulación de las restricciones al comercio, los sobrantes de producción local serían exportados, mientras que la falta de recursos se resolvería con importaciones. En este marco, la regulación del Estado no era necesaria.
Visto en perspectiva, y tal como se advierte en la Figura 1, si bien generó un cambio importante en los precios relativos ${ }^{3}$, esta política fue posible por un doble efecto. El primero de ellos fue la sanción de la Ley de Convertibilidad en 1991, que igualó el tipo de cambio en 1 peso $=1$ dólar. Las estimaciones realizadas evidencian que el tipo de cambio real alcanzado se encontró dentro de los más bajos de la historia del país. Tomando el promedio del período 1991-2001 se ubicó en un $51 \%$ por debajo de 1930 1990 (que, en sí mismo, tuvo fuertes oscilaciones). En la práctica, esta medida posibilitó que los precios de estos bienes se pudieran dolarizar con bajo impacto en moneda local. El segundo elemento por considerar es que durante esos años el precio del barril de crudo fue bajo comparativamente con otros períodos (30 dólares el barril, la mitad de la década previa y un cuarto del pico máximo de la siguiente). En suma, en la década de 1990 el Gobierno pudo dolarizar los bienes energéticos y hacerlos converger con los precios internacionales por el hecho de que se trató de un decenio en el que coexistieron un tipo de cambio real atrasado y precios internacionales bajos en términos históricos.

2 Integrantes del Gobierno y empresarios se pronunciaron en este sentido. Óscar Parrilli, diputado del Gobierno, expresó en el debate por la privatización de YPF: "No deseamos que el Estado sea el actor principal de la economía [...]. Existe un acuerdo en la teoría económica de que los mercados competitivos son los más eficaces y los únicos capaces de satisfacer la demanda con una mayor oferta a precios más bajos maximizando así el bienestar económico general" (Diario de Sesiones, 1992, p. 3.164). Por su parte, el vicepresidente ejecutivo de la Compañía General de Combustibles (CGC), del grupo Soldati, expresó: "Hoy es el cliente el que asegura la competencia y la diversidad al requerir de nosotros más calidad, mejores servicios y nuevos productos. Qué mejor 'regulación' podemos tener que la 'lealtad a la marca' por parte de nuestros clientes" (Actualidad Energética, 1992, p. 31).

3 Una serie de trabajos de autores de diversa extracción ideológica dieron cuenta de los importantes aumentos registrados durante esos años (Azpiazu, 2003; FIEL, 1989, 1999; FLACSO, 1998). 


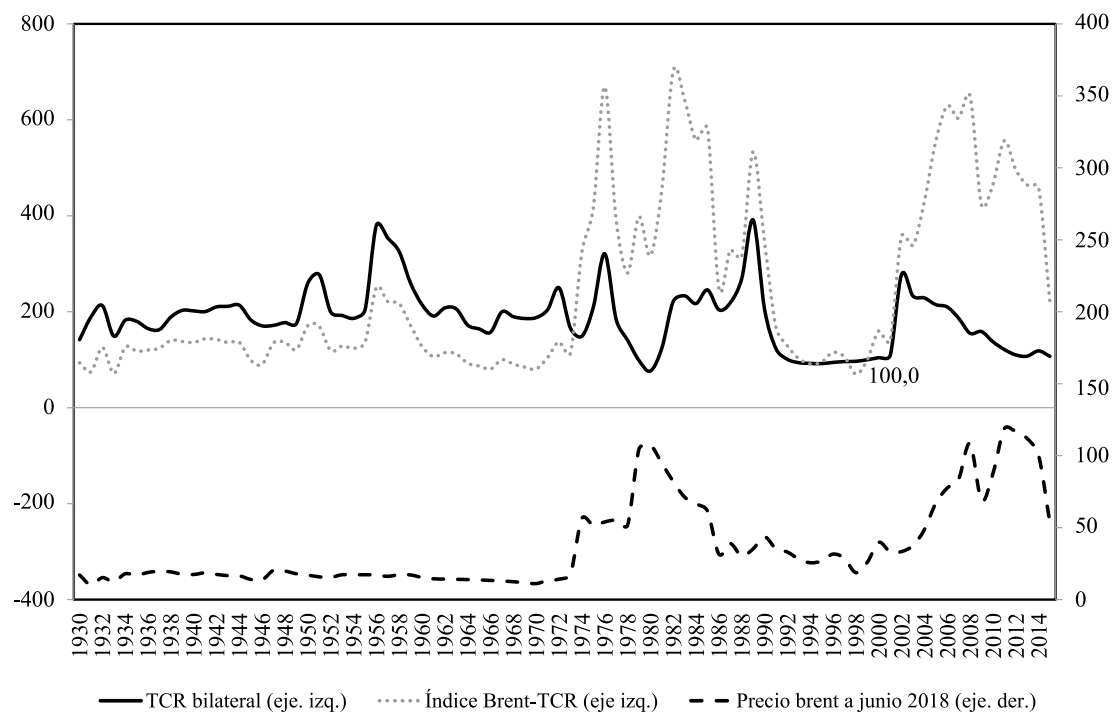

Figura 1. Evolución del TCR bilateral con Estados Unidos y del precio Brent del crudo a precios constantes de 2018 y del índice Brent-TCR 1930-2015 (en dólares por barril y número índice 1999=100).

Fuente: elaboración propia con base en datos de INDEC, BCRA, Ministerio de Energía, Bureau of Labor Statistics y Department of Energy.

Distinto fue el escenario que se abrió en 2002 con la devaluación del peso y el persistente aumento de la cotización internacional del barril desde mayo del 2004, período en el que coincidieron un tipo de cambio real elevado históricamente $(69 \%$ en promedio por encima de la década de 1990, con una etapa inicial, hasta 2007 en la que el TCR fue $125 \%$ superior) y el precio del crudo más alto de la historia. De allí que los gobiernos que se sucedieron hasta 2015 desacoplaron los precios locales de los internacionales (Arceo, 2018; Kozulj, 2005; Navajas, 2017; Soares \& Naritomi, 2018).

Además de la desregulación, los decretos habilitaban la concesión de activos de la petrolera estatal al capital privado. Se trató de un proceso de fragmentación de YPF, que implicó la concesión de 147 áreas (equivalentes al 50\% de las reservas del país), poliductos, terminales marítimas, la venta de tres refinerías, veinte embarcaciones y el despido de 35689 trabajadores (el 96\% de la planta vigente en 1989, que pasó a operar con 4482 empleados luego de algunas incorporaciones que vieron alteradas sus condiciones de trabajo), entre los más relevantes (Barrera, 2014; Palermo, 2017). Así, la fragmentación de YPF, según enfatizaba el interventor de la compañía (José Estenssoro), posibilitaría el ingreso de nuevos oferentes al mercado y contribuiría a la generación del mencio- 
nado "mercado de competencia" como consecuencia de la desconcentración de actividades (Estenssoro, 1992).

En esta línea, se privatizaron tres de las ocho refinerías que tenía YPF. En 1992 fue vendido el $70 \%$ del capital social del poliducto y la refinería Campo Durán a los grupos locales Pérez Companc (28\%), Pluspetrol (21 \%), Isaura $(10.5 \%)$ y Astra (10.5\%), conservando el $30 \%$ restante la YPF S.A. privatizada, los cuales conformaron la firma Refinería del Norte (Refinor). Las otras dos refinerías, enajenadas en 1993 , fueron Dock Sud y San Lorenzo. La primera fue adquirida en su totalidad por Dapsa (grupo Soldati) que operaba desde 1973 y en 1989 explicaba el $0.4 \%$ de la capacidad de refinación del país. La segunda la compró el conglomerado formado por CGC (42.5\%), también de Soldati, Pérez Companc (42.5\%) y Petroquímica Argentina S.A. (PASA, de Pérez Companc) (15.0 \%).

Por la totalidad de las refinerías que aportaban el 9.5\% de la capacidad de destilación de la Argentina, el Estado recaudó 88,1 millones de dólares. Más allá del ingreso percibido por las arcas públicas, lo sustancial del proceso fue que le permitió a ciertos grupos económicos locales que controlaban un tercio de la producción de crudo del país (Astra, Pluspetrol, CGC y Pérez Companc, fundamentalmente) alcanzar un importante proceso de integración vertical en toda la cadena hidrocarburífera y en el mercado ampliado de la energía (Barrera, 2014; Ministerio de Economía, 1994).

La reestructuración propuesta por el Gobierno, en los objetivos declarados, buscaba incrementar la competencia del mercado "en igualdad de condiciones para todas las empresas que actúan en el sector [...] en beneficio del interés general y de los usuarios" (Decreto 1212 de 1989); sin embargo, las normativas sancionadas fueron contrarias a la consecución de dichos objetivos. En realidad, los estudios existentes señalan que la fragmentación propició un formidable proceso de centralización del capital y de reconcentración e integración, en manos privadas, de la producción hidrocarburífera local (Azpiazu, 2003; Barrera, 2014; Kozulj, 2002; Kozulj \& Bravo, 1993; Mansilla, 2007).

Tal como señala la Figura 2, luego de la desregulación de la actividad y de la privatización de los activos de YPF, el mercado argentino se mantuvo altamente concentrado tanto en procesamiento como en comercialización 
de los principales combustibles, con índices ${ }^{4}$ que descendieron luego de la privatización, pero que posteriormente recuperaron valores previos por las fusiones y adquisiciones de empresas 5 . Se trata, en última instancia, del paso de un mercado oligopólico público a una morfología levemente más segmentada "de tipo oligopólico [privado] con liderazgo de precios por parte del actor predominante (YPF)" (Kozulj, 2002, p. 22). Contrariamente a lo que señalaba el Gobierno, esta morfología de mercado se alcanzó por una serie de trabas normativas que limitaban la competencia. La Ley 23.966 y su Decreto Reglamentario 2.485 de 1991 establecían como límites para importar la necesidad de haber comercializado no menos de $100000 \mathrm{~m}^{3}$ durante el año anterior para poder inscribirse en el Registro de Empresas Petroleras. Pero, por otro lado, debían poseer un patrimonio no inferior al impuesto más alto creado por la Ley 23.966 (nafta súper de más de 92 RON) sobre un volumen de $50000 \mathrm{~m}^{3}$ de combustible (cercano a los 25 millones de dólares). Incluso, la normativa agregó otro obstáculo a la competencia al diferenciar entre los importadores y los refinadores locales, ya que mientras los primeros debían tributar el ITC "juntamente con los derechos de importación y el impuesto al valor agregado", a los segundos se les permitía abonarlo "con la entrega del bien, emisión de la factura o acto equivalente, el que fuera anterior".

Así, producto de las barreras "naturales" que contribuían a impedir la convergencia de los precios locales con los externos (vinculadas a la poca capacidad de almacenaje, ausencia de profundidad en el calado e infraestructura portuaria, etc.), pero, principalmente, como consecuencia de las barreras "político-institucionales" mencionadas, se consolidó un mercado altamente concentrado (Azpiazu, 2003; Gerchunoff, 1994; Gerchunoff \& Cánovas, 1995). Este análisis es de sustancial relevancia porque permite ver ciertos "vicios" en el origen del proceso con "sesgo" hacia el sector privado, que afectaron su posterior funcionamiento.

$4 \quad$ El índice que se construyó para analizar este fenómeno es el Herfindahl-Hirschman $(\mathrm{IHH})$, que se calcula sumando los cuadrados de las distintas cuotas de mercado de cada uno de los participantes, lo que confiere un peso superior a aquellas firmas que tienen una participación mayor en la actividad. En caso de existir un monopolio, el índice alcanzará un valor de 10000 y a medida que se incrementa la competencia en la actividad, el indicador tenderá a acercarse a 0 . Así, existen tres cortes para medir la morfología del mercado: cuando el índice refleja un valor por encima de 2500 puntos (hasta 10000 ), se estima que es un mercado "altamente concentrado"; en cambio, entre valores superiores a 1500 y menores a 2500 , se considera que la actividad se encuentra "concentrada"; mientras que con índices inferiores a 1500 se puede establecer que es un mercado "desconcentrado" (Kozulj, 2002; Novara, 1997; U.S. Department of Justice, 2010).

5 El primer cambio se produjo con la fusión entre Isaura, Astra y CGC en el campo de la refinación, que dio origen a Eg3, a partir de la cual concentraron alrededor del $7 \%$ de la refinación de crudo y el $10 \%$ y $12 \%$ de la venta de naftas y gasoil, respectivamente. El siguiente suceso fue la compra de YPF S.A. por parte de la petrolera española Repsol en 1999, que era propietaria de Eg3 (ya que Astra, controlada por el conglomerado ibérico, había adquirido la casi totalidad de acciones de la compañía). Esa adquisición propició un incremento notable del IHH que alcanzó valores similares a los del período estatal. La relativa desconcentración registrada en 2002 se debió a la transferencia de los activos de Eg3 a Petrobras. El incremento de las ventas de Repsol-YPF hasta 2010 por encima de sus competidores, posibilitó retomar la mayor concentración. 


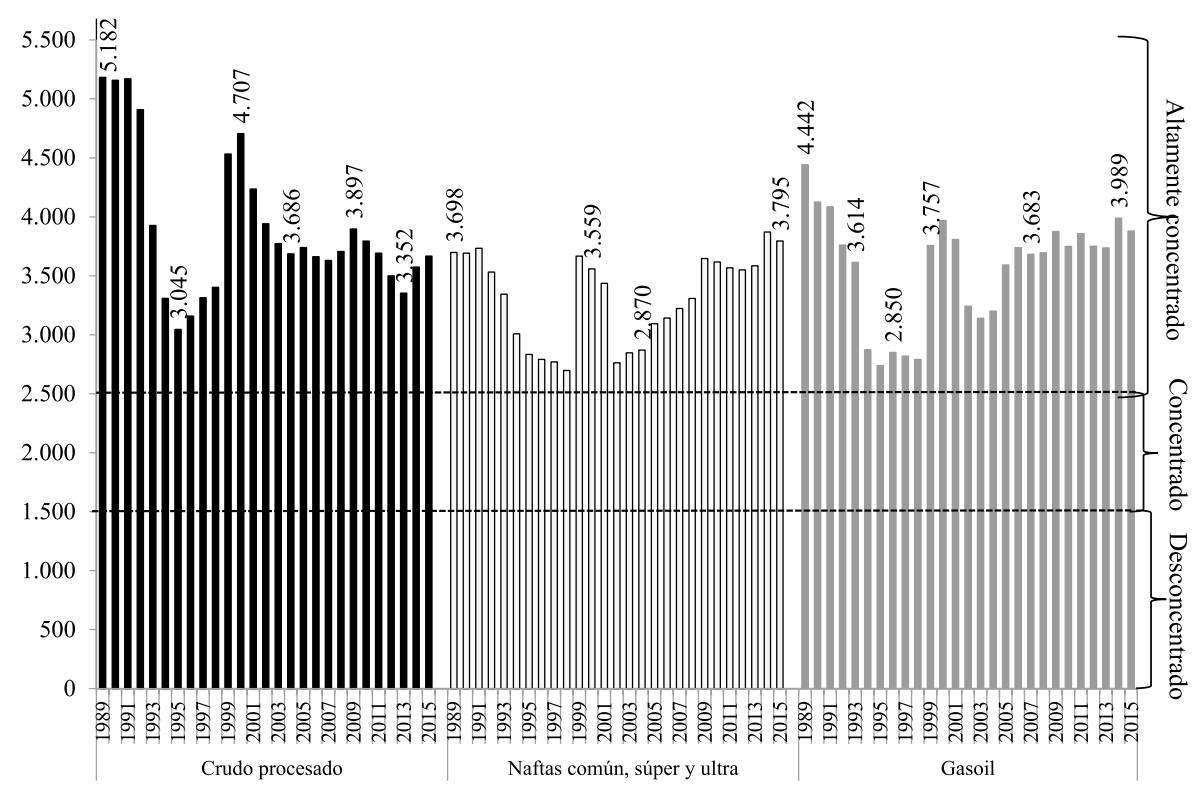

Figura 2. Grado de concentración del mercado de crudo procesado, de naftas y de gasoil con base en el índice Herfindahl-Hirschman, 1989-2015 en unidades.

Fuente: elaboración propia con base en estadísticas de la Secretaría de Energía y el IAPG.

\section{LA NUEVA ESTRUCTURA DEL MERCADO SECUNDARIO DU- RANTE LA DÉCADA DE 1990: DEL OLIGOPOLIO PÚBLICO AL OLI- GOPOLIO PRIVADO}

El análisis del perfil del downstream luego de la reestructuración permite advertir que no se alcanzaron grados significativos de desconcentración. Ello se deriva, principalmente, de que YPF S.A. mantuvo una participación considerable a partir de las destilerías que conservó y de que, aun cuando el Decreto 1.212 de 1989 desreguló la "instalación de capacidad adicional de refinación", en lo sucesivo no se amplió la formación de capital tendiente a incrementar dicha capacidad instalada. Basta simplemente analizar la Figura 2 para corroborar que, si bien la fragmentación devino inicialmente en una leve desconcentración del mercado, en ningún momento dejó de ser "altamente concentrado". En efecto, cualquiera sea el segmento que se considere, procesamiento de crudo o venta de naftas o gasoil, la transferencia de las refinerías (que culminó en 1993) marcó la bisagra del proceso de reducción relativa del poder de mercado de YPF S.A., que redundó en disminuciones del índice Herfindahl-Hirschman, pero que, en ningún caso, descendió de los 2.697 puntos.

Una característica de este proceso es que la pérdida de participación de YPF 
como resultado de la fragmentación fue acaparada por los principales actores que operaban ambos mercados. En efecto, las siguientes competidoras, Esso y Shell, absorbieron parte de la refinación de crudo al pasar del $14.0 \%$ al $18.5 \%$ entre 1989 y 1995 , y del $13.3 \%$ al $16.9 \%$, respectivamente. Pero también aprovecharon el repliegue de YPF las firmas que adquirieron sus activos, Refinor (originariamente propiedad de Pérez Companc, Pluspetrol, Astra e YPF) y Refisan (Pérez Companc y CGC). De este modo, en 1995 más del $90 \%$ de la capacidad de refinación del país estuvo concentrada fundamentalmente en cinco compañías privadas: YPF S.A./Repsol-YPF, Esso, Shell y Pérez Companc.

La nula ampliación de la capacidad instalada fue resultado de las decisiones del oligopolio privado para exportar el producto sin procesar, apuntando a vender en el exterior los saldos existentes, en lugar de agregarle mayor valor en el país $^{6}$. Aun cuando a escala internacional, según estadísticas publicadas por la Agencia de Energía de los Estados Unidos, entre 1989 y 2001 la capacidad de refinación aumentó el $16.2 \%$ y en Centro y Sudamérica el crecimiento fue del $19.6 \%$, en Argentina se contrajo 8.3\% hasta 2000 (Figura 3). Luego de años de expansión de la capacidad instalada por parte de la YPF estatal (ECyT-ar, 2016; Manzanelli \& Barrera, 2018), durante los noventa la política pasó por exportar el crudo para maximizar la rentabili$\mathrm{dad}^{7}$. Derivado de esta estrategia, los períodos de expansión y contracción de la refinación de petróleo estuvieron condicionados por los ciclos de la economía doméstica, no ya de la internacional. En términos más específicos, y de acuerdo con los datos aportados, la refinación de crudo en 1989, que había descendido un $14.6 \%$ si se comparara con 1980, inició un proceso de expansión alentado por el mayor consumo doméstico producto del crecimiento económico de los primeros años de la convertibilidad. Este aumento se resintió en 1995 con el impacto de la denominada "crisis del tequila" (que provocó la devaluación de su moneda, producto de la masiva fuga de capitales) y con el posterior comienzo de la crisis económica local en 1998, que culminó en 2001/2002 con el estallido del patrón de acumulación de valorización financiera que predominó desde 1976 (Basualdo, 2019). Así, entre el período analizado, la expansión del petróleo procesado estuvo en torno del $17.2 \%$, con un uso de la capacidad instalada que promedió el $72.6 \%$.

$6 \quad$ Mientras en 1990 el $16 \%$ de las exportaciones energéticas correspondían a bienes con bajo valor agregado, en 2001 estas habían ascendido al $73 \%$, habiendo llegado al $81 \%$ en 1996 (principalmente petróleo crudo y gas natural).

7 Al respecto, a mediados de la década, Estenssoro afirmaba: "Hay dos razones por las que enfrentamos circunstancias en que nos conviene más exportar directamente petróleo crudo que productos derivados con valor agregado. [...] O bien [porque] somos ineficientes o bien porque la competencia internacional de los precios es muy marginal por la gran capacidad de destilación instalada. Alternativamente, ambas cosas son ciertas en la Argentina" (Estenssoro, 1995, p. 17). La reducción en la producción de ciertos derivados del petróleo era considerada como una oportunidad para ampliar las exportaciones del recurso sin procesar: "La menor producción de estos productos [gasoil y fuel oil] permitió la elaboración de mayor cantidad de productos de mayor margen y un aumento en los volúmenes de crudo disponible para exportación" (YPF, 1994). 


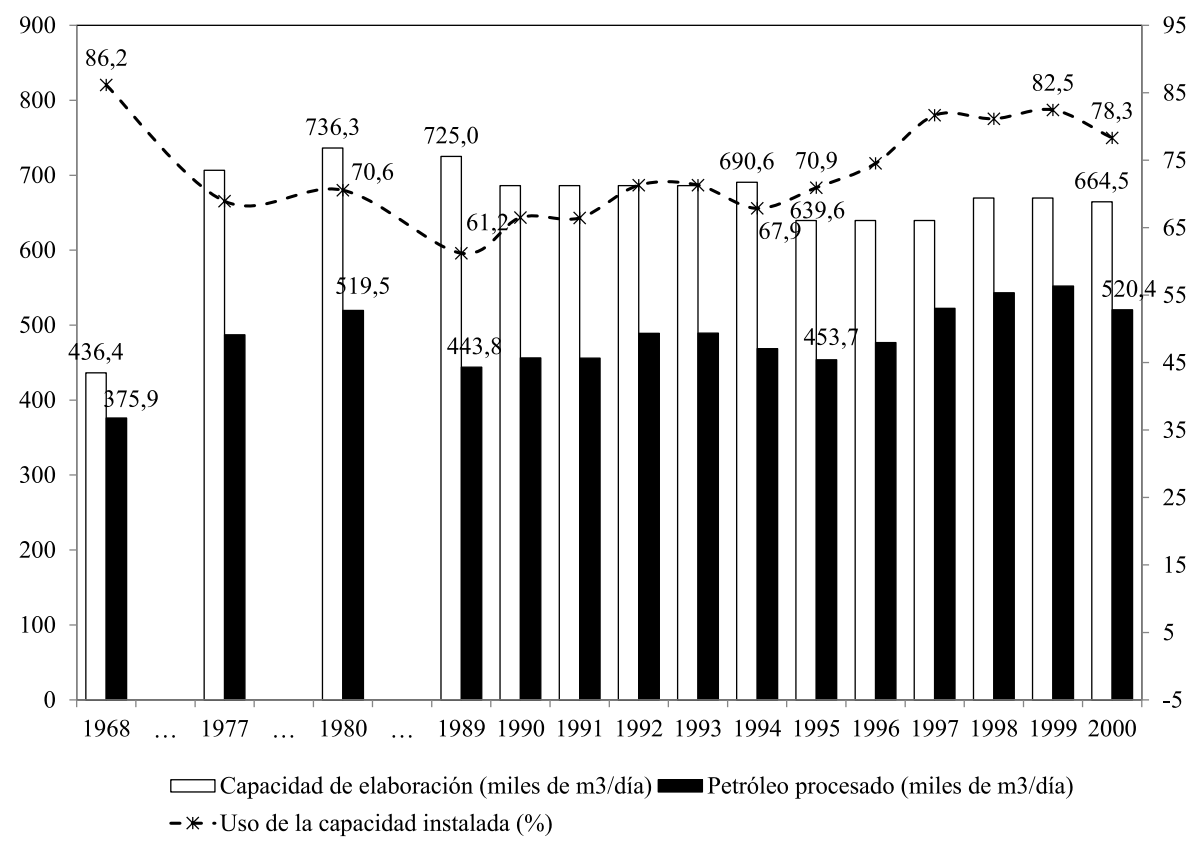

Figura 3. Evolución de la capacidad de elaboración de crudo de las refinerías nacionales, del petróleo procesado y del uso de la capacidad instalada, 1968, 1977, 1980, 1989-2000 (en miles de barriles/día y porcentaje).

Fuente: elaboración propia con base en información de la Secretaría de Energía.

Considerando que el objetivo del oligopolio refinador no era posicionarse como una plataforma de exportación de derivados con valor agregado, la estrategia de las compañías se orientó a mejorar las productividades de las plantas y la calidad de los productos obtenidos. Así lo expresaba Smaal, gerente de Refinación de Shell: "Dado que la capacidad de destilación primaria parece suficiente, los esfuerzos están focalizados hacia la mayor conversión de residuos. En este sentido, procesos de conversión como Craqueo Catalítico, Hidro Craqueo, Craqueo Térmico y dentro de este campo el antiguo proceso de Coqueo
Retardado siguen concentrando la atención de los investigadores" (Smaal, 1998, pp. 9-10). Así, las empresas desplegaron estrategias de posicionamiento a través de diferenciarse por calidad de producto y no por precio. De allí que, aun cuando se evidenció una retracción de la capacidad primaria de destilación, se realizaron inversiones sobre los procesos que permitían incrementar la calidad de los productos mediante la adición de mayor octanaje a las naftas y la eliminación del plomo.

Una perspectiva analítica complementaria al análisis de la cantidad refinada 
surge de estudiar qué sucedió con los precios de los combustibles vendidos. Para ello, se consideró la evolución de la nafta súper comercializadas en el país durante el período bajo análisis.

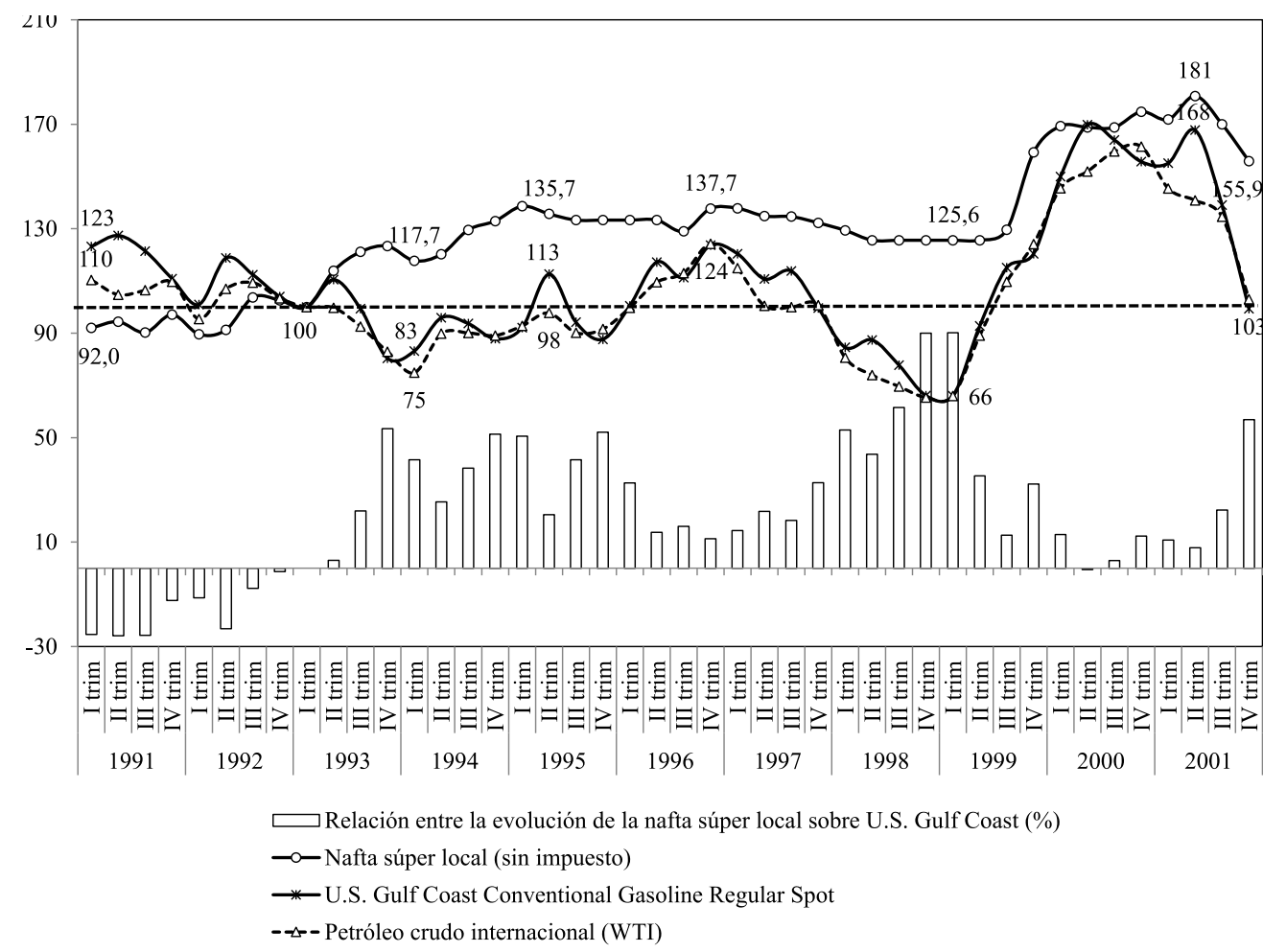

Figura 4. Evolución de los precios en dólares de la nafta súper sin impuestos local, de la US Gulf Coast Conventional Gasoline Spot y del petróleo internacional, I. trim. 1991- IV trim. 2001 (número índice I trim. 1993=100).

Fuente: elaboración propia con base en estadísticas de la Secretaría de Energía y la EIA.

La Figura 4 presenta una comparación entre la evolución de los precios en dólares de las naftas "súper" sin impuestos en Argentina, el spot $^{8}$ de la costa del Golfo de los Estados Unidos y del petróleo crudo WTI. Al ser un bien transable, y bajo el supuesto de que la desregulación eliminó las barreras que impedían la "internacionalización" del mercado, debería haber convergencia de precios y tendencias; sin embargo, si bien se advierte una notoria correlación entre los dos productos internacionales, ya que el precio de la nafta spot osciló

8 El mercado spot es aquel que se contrata de forma "inmediata" (sin contratos a término) y cuyo pago se realiza en efectivo. 
de forma similar a los cambios producidos en el precio del petróleo crudo WTI, esto no sucedió con la nafta local. Entre el primer trimestre de 1991 y el primero de 1993 (punto bisagra que coincide con el año en que se finalizó con la venta de las refinerías de YPF), los precios en moneda extranjera crecieron levemente en Argentina, en un contexto de caída de la cotización internacional. Esto se debió al proceso de convergencia del precio del barril interno al internacional, que aconteció principalmente entre 1989 y 1992 (Kozulj, 2002).

En una segunda etapa, luego de la conformación del "oligopolio privado" desde 1993, los datos señalan que la "liberalización de las fuerzas del mercado" no se tradujo en un mercado competitivo, ya que las variaciones en el precio local de la nafta, a diferencia de la US Gulf Coast, posee cierta autonomía de los ciclos alcanzados por el valor del WTI. Los períodos de caída de este último fueron acompañados por similar dinámica del combustible internacional, mientras que el comportamiento del precio de la nafta doméstica refleja cierta estabilidad o leve contracción. Por su parte, ante incrementos de aquellos, la respuesta doméstica fue de una expansión con mayor grado de intensidad. Así, al tomar como punto de comparación el primer trimestre de 1993 e igual período de 1999, el alza del precio de la nafta local alcanzó el $26 \%$, mientras que su par internacional descendió el $34 \%$. A su vez, si se considera la variación hasta el final del período, los resultados son $56 \%$ y $3 \%$, respectivamente (Figura 4 ).

La eliminación de las regulaciones del Estado, lejos de generar una dinámica competitiva, habilitó la emergencia de posiciones dominantes del "oligopolio privado" a través de la profundización de las "fallas de mercado" señaladas. Si bien el ejercicio abusivo del poder oligopólico se advierte en cualquiera de las etapas del ciclo analizadas (ya sea en el ascendente como en el decreciente), la disociación de los precios en la fase descendente alcanzó niveles superlativos. Según datos publicados por el Ministerio de Economía, en diciembre de 1998 el precio de la nafta súper sin impuestos fue un $109.0 \%$ superior al precio de paridad de importación (23 y 11 centavos, respectivamente) $)^{9}$ (MECON, 2001a). Esta dinámica se advirtió también con el gasoil que en febrero de 1999 el precio en el mercado interno también duplicó el de paridad de importación. La distorsión del sector debido a la morfología concentrada constituida luego de la reestructuración permitió que, ante períodos de persistente baja del precio del crudo internacional $\mathrm{y}$, consecuentemente, de los combustibles en el mercado externo, las firmas privadas domésticas pudieran sostener el precio interno con la consecuente captación de ganancias extraordinarias (Di Sbroiavacca).

\footnotetext{
$9 \quad$ No parece ser un hecho aislado que en mayo de este año se sancionara el Decreto 518 de 1998, que modificó la normativa que les impedía a los importadores liquidar el ITC con la entrega del bien o factura, poniéndolos en igualdad de condiciones con los actores nacionales.
} 
Según este estudio oficial (MECON, 2001a), entre 1997 y 2001 los precios locales fueron alrededor del $30 \%$ superiores a los que se podrían haber obtenido de comprar en el exterior el producto y colocarlo en el mercado doméstico, sin que el Gobierno aplicara la Ley de Defensa de la Competencia (n. ${ }^{\circ} 25.156$ ) que tipifica este tipo de actos abusivos y establece penas para aquellos actores que restrinjan la competencia del mercado.

Ante este evidente desacople de los precios locales respecto de los internacionales, el entonces secretario de Combustibles, Alberto Fiandesio, sostuvo que según anunciaban las compañías, estas no corregían los precios, porque "como han invertido mucho en los últimos años, necesitan recuperar las inversiones realizadas" (citado en Ferreira, 1998, p. 3). Pese a ello, los costos de algunas de las inversiones ejecutadas, que se centraron principalmente en mejorar la calidad de los combustibles y no en la expansión de la capacidad primaria de destilación, fueron absorbidos por el Estado a través de reducciones impositivas (Esteves, 1998, p. 11). A su vez, el argumento de las reformas era que la "desregulación" impediría a los productores fijar el pre- cio (para "recuperar inversiones"), ya que este sería un elemento "dado" por el mercado externo. La realidad señala que la constitución de barreras institucionales y naturales y la decisión del Estado de relegar su carácter regulador, habilitaron la conformación de "precios de oligopolio" $"$.

La Figura 5 permite advertir el notable incremento del margen apropiado por las refinerías derivado de la morfología del mercado argentino. En este sentido, al analizar la evolución entre 1992 y 2001, el margen bruto se incrementó $86 \%$, el punto más alto del período considerado; sin embargo, si en vez de medirlo en términos absolutos, se compara en términos relativos, es decir, como porcentaje del precio del crudo, el pico de la serie se alcanza en 1998, dado que en dicho año el valor del crudo descendió, pero no el precio de los derivados (Figura 4). La posterior recuperación del precio del crudo (que llegó a su máximo nivel en 2001) permitió que en términos absolutos la apropiación fuera mayor, pero dado que los derivados se incrementaron en menor medida, el margen relativo descendió a los niveles de 1992.

10 Por "precio de oligopolio" se entiende aquel generado por la morfología concentrada del mercado que permite una captación de "renta oligopólica extraordinaria" por parte de los refinadores y comercializadores. 


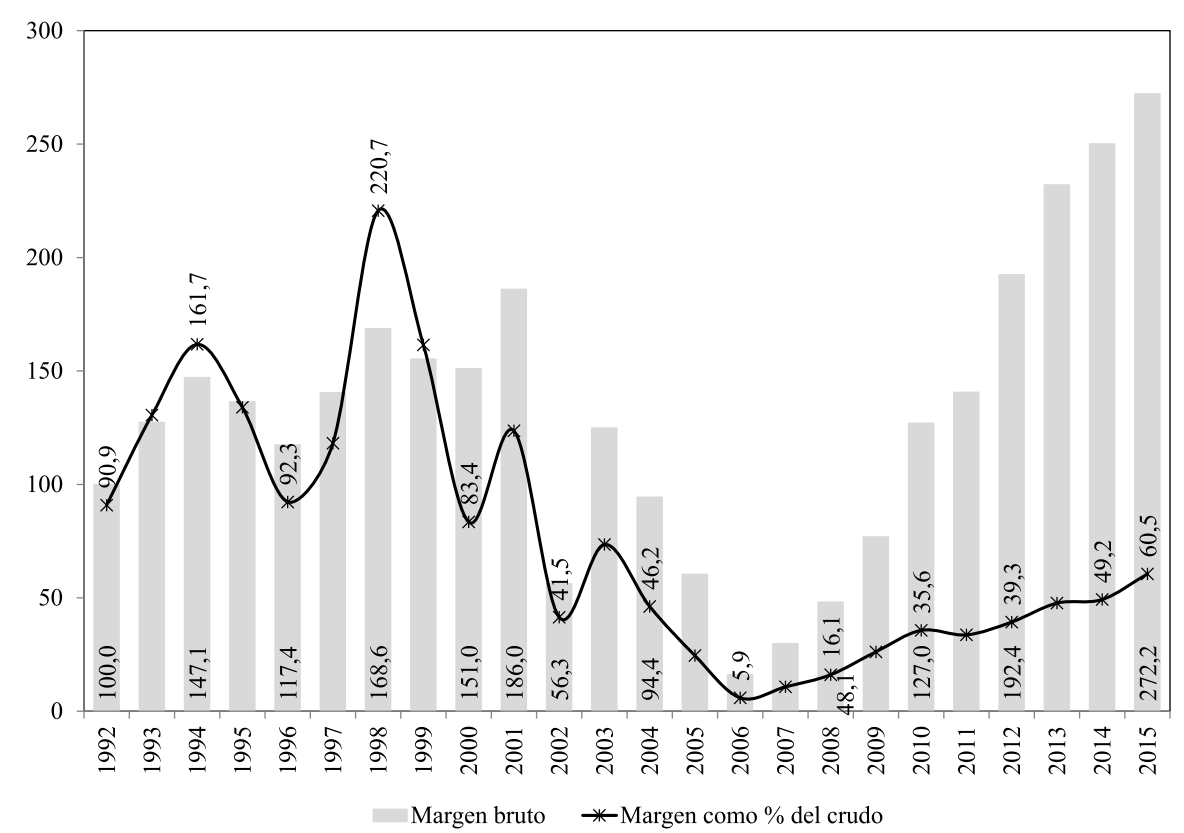

Figura 5. Evolución del margen bruto de refinación en términos absolutos y relativos (como porcentaje del valor del crudo) 1992-2015 (número índice 1992=100 y \%).

Fuente: elaboración propia con base en datos de la Secretaría de Energía.

En definitiva, con base en el análisis realizado a través de las distintas metodologías, las reformas del downstream, que tenían por objetivo declarado lograr la convergencia de los precios internos con los internacionales, producto de las normativas sancionadas por el propio Gobierno y de la existencia de barreras naturales, transfirieron la capacidad regulatoria que tenía el Estado a cinco grupos económicos y conglomerados extranjeros, lo que les permitió capturar parte importante de la renta petrolera durante la convertibilidad haciendo abuso de la posición dominante.
LA DINÁMICA DEL OLIGOPOLIO REFINADOR PRIVADO BAJO LA NUEVA ESTRUCTURA DE PRECIOS RELATIVOS DE LA POSCONVERTIBILIDAD

La crisis económica que comenzó en 1998 y tuvo su epicentro en 2001/2002 generó un cambio profundo de los precios relativos cuando el 6 de enero de 2002 se puso fin al tipo de cambio convertible y la moneda doméstica tuvo una devaluación real del $200 \%$ durante ese año. La contracción económica (-10.9\% en 2002) y el proceso inflacionario que 
se desató generaron un aumento notable de la desocupación (arribó al $24.8 \%$ ), de la pobreza (que llegó al $54.3 \%$ de la población), una sensible pérdida del salario real de los trabajadores registrados (-21.3\%) y una caída de 7 puntos porcentuales en la distribución funcional del ingreso (CIFRA, 2013).

En este marco crítico, el Gobierno interino de Eduardo Duhalde (20022003) sancionó la Ley de Emergencia Económica y Reforma del Régimen

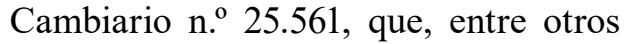
elementos, habilitó nuevamente el cobro de derechos de exportación a los hidrocarburos por el plazo de cinco años (prorrogados hasta 2017) ${ }^{11}$, con el objetivo de contener los precios y aumentar la recaudación del Estado. Esta política siguió con los gobiernos de Néstor Kirchner (2003-2007) y Cristina Fernández (2007-2015), ampliándose aún más las alícuotas de estos derechos de exportación en un contexto de incrementos notables de la cotización del crudo (Figura 1), que generó el rechazo por parte del sector privado ${ }^{12}$.

Este nuevo período implicó un cambio en el modo de intervención estatal en la economía y en el sector hidrocar- burífero, a partir de una estrategia de contención de precios, pero sin que se haya implementado un proceso de regulación integral de la actividad. Fue recién a mediados del 2012, en el marco de la expresión de la crisis del modelo energético implementado en la década de 1990, cuando el Gobierno de Cristina Fernández generó un cambio del sector a través de la expropiación del 51\% de las acciones que Repsol S.A. tenía en YPF S.A. y se declaró de interés público nacional el logro del autoabastecimiento de hidrocarburos.

Desde el inicio de este período existieron tensiones entre el Gobierno (inicialmente de Duhalde) y las empresas productoras de petróleo y refinadoras. Una de estas instancias fue en marzo de 2003, cuando estaba por vencer el primer acuerdo realizado en enero de ese año ${ }^{13}$. Allí se había establecido que las comercializadoras no siguieran aumentando los precios de los combustibles y las compañías productoras de crudo se comprometían a vender el crudo a 28,5 dólares el barril (por debajo del internacional). A diez días de cumplirse el plazo establecido, la cotización externa ascendió a 35 dólares, lo que generó una fuerte presión de los productores para renunciar el acuerdo y liberar los

11 Inicialmente, se implementó un derecho de exportación del 20\% (Decreto 310 del 2002). Para analizar cómo fueron incrementándose en los años siguientes, se recomienda Barrera (2012).

12 Sobre el impacto en el sector primario en este período existen diversas visiones (Apud et al., 2011; Barrera, 2012, 2014; Hancevic, Cont \& Navajas, 2016; Kozulj, 2012; Sabbatella \& Serrani, 2011; Serrani, 2012; Wainer \& Arceo, 2017). Aquí solo se agrega que, pese a que los derechos de exportación redujeron los precios internos, la rentabilidad del período fue mayor a la de la década de 1990, ya que la renta petrolera creció al compás del incremento del precio internacional. Sin embargo, esta renta capturada por las compañías en Argentina fue menor que la del escenario exterior, razón por la cual las compañías redujeron al mínimo las inversiones como mecanismo de presión.

13 Para una cronología de los hechos, se recomienda Serrani (2012). 
precios $^{14}$ (Canton, 2002). La respuesta del ministro de Economía Lavagna fue presionar a las compañías anunciando que se aplicarían derechos de exportación del $100 \%$ sobre las exportaciones de petróleo, para "absorber la renta extraordinaria por encima de los 30 dólares" y evitar los aumentos (Longoni, 2002a), lo que posibilitó alcanzar un nuevo acuerdo el 31 de mayo (Resolución n. ${ }^{\circ} 220$ del 2002).

Estas tensiones entre el Gobierno y el sector privado persistieron y se ampliaron durante el Gobierno de Néstor Kirchner y Cristina Fernández. El crecimiento del PIB a una tasa del 6.3\% anual entre 2002 y 2011 fue de la mano de una expansión del consumo de bienes energéticos, incluidos los combustibles. La administración de Kirchner también entendía que en un contexto de salarios deprimidos y un entramado industrial que comenzaba a recuperarse luego de 16 meses de contracción ininterrumpida, los precios internos - principalmente los de la energía - debían estar "contenidos" para mejorar la competitividad de la economía. En este sentido, el 5 de junio Kirchner firmó el "tercer acuerdo de estabilidad", que permitió ampliar el convenio para mantener los precios de los combustibles desvinculados del escenario internacional.
La reactivación de la economía, la recuperación del consumo a los niveles previos a la crisis y el "boom" de ventas de automóviles generaron importantes aumentos en la comercialización de los derivados del petróleo, situación que se expresó en tasas anuales de crecimiento significativas, en torno del $3.5 \%$ en gasoil y $7.2 \%$ en naftas (Figura 6). El análisis de este flujo de productos no solo permite comprender el sector en sí mismo, sino la dinámica económica en general, a partir del impacto de las diversas recesiones o crisis económicas en el consumo - $\mathrm{O}$ en la sustituciónde combustibles. Así, los años de contracción o desaceleración económica (1990, 1998, 2002, 2009) se tradujeron en caídas de las ventas de los principales derivados o la sustitución de un combustible por otro de menor precio. De este modo, tomando el caso del gasoil, luego del descenso registrado en 1990 alcanzó un vigoroso crecimiento hasta 1998 (que redujo los saldos exportables), año en el que la economía ingresó en la recesión económica que culminó con el fin del "modelo de valorización financiera y ajuste estructural" en 2002. La expansión de la producción de gasoil se evidencia como uno de los puntos positivos de esta etapa y estuvo asociado, centralmente, a la mejora en los procesos productivos de las refinerías, como se señaló. Desde 1998, en mate-

14 En palabras del presidente de la Cámara de la Industria del Petróleo y de Shell, Juan José Aranguren, "Para que se cumpla el vaticinio de Economía de que no habrá aumentos de precios debe cumplirse una de tres cosas. Que baje el precio del petróleo, que baje la carga impositiva de los combustibles o que se vuelva a los controles de precios, y eso es totalmente indeseable porque la experiencia ha demostrado que termina en desabastecimiento y mercado negro" (Canton, 2002). Por su parte, Tomas Hess, de ESSO, sentó posición al manifestar que "elevando al $100 \%$ las retenciones no se va a poder exportar ni importar, ni contener la suba de los precios, y también habrá desabastecimiento" (Longoni, 2002b). 
ria de ventas, se inició una nueva fase de auge que se resintió con el impacto local de la crisis internacional de 2009 y la sequía del "campo". Parte de la explicación de este estancamiento de las ventas de gasoil en el último lustro bajo análisis, radica en el cambio en materia impositiva del diesel en la década de 2000, ya que se alteró la menor carga de impuestos que poseía desde la década de 1980 , a tal punto que se equipararon sus precios finales con las naftas, lo que desalentó su uso ${ }^{15}$.

Este importante crecimiento de las ventas que se registró desde la reactivación de la economía no fue acompañado con una creciente formación de capital destinada a la ampliación de la capacidad instalada para la refinación. Así, durante los primeros años del nuevo siglo, este acotado número de empresas operó con la capacidad ociosa que poseían sin la necesidad de generar mayores inversiones para cubrir la mayor demanda. Sin embargo, hacia 2007 se alcanzó el límite de destilación, lo que se expresó en un importante déficit productivo con la consecuente profundización de las importaciones de estos productos.
El análisis del gasoil permite advertir que la saturación se alcanzó unos años antes, en tanto que 2004 fue el último con excedentes, que disparó sus importaciones entre 2002 y 2013, las cuales explicaron el $36 \%$ de las importaciones de combustibles del país (Serrani \& Barrera, 2018). Distinto es el escenario de las naftas, dado que la imposibilidad de cubrir la demanda con producción local emergió recién en 2010 y con volúmenes más reducidos $(2.2 \%$ de la elaboración de 2011, frente al $13.0 \%$ en gasoil).

En este marco, a diferencia de la década de 1990 en la que el posicionamiento dominante les permitió capturar renta por el diferencial de precios locales y externos, en la década de 2000 se desplegó una serie de políticas que alteraron drásticamente la relación con los precios internacionales, lo que redundó en diversas estrategias por parte del oligopolio energético. El faltante de combustibles líquidos en el mercado interno comenzó a forzar importaciones, lo que contribuyó a que los precios internos tendieran a alinearse con los de paridad de importación.

15 La marcada caída de la comercialización de naftas (común y súper) entre 1998 y 2004 (-39.0 \%) tuvo como contrapartida un importante incremento del consumo de gas natural comprimido (GNC) (115.6\%), asociado a un crecimiento del parque automotor a GNC (el cual pasó de 459000 a 1,4 millones de vehículos en el mismo período) que permitió, en momentos de crisis, la sustitución por una variante más económica. 


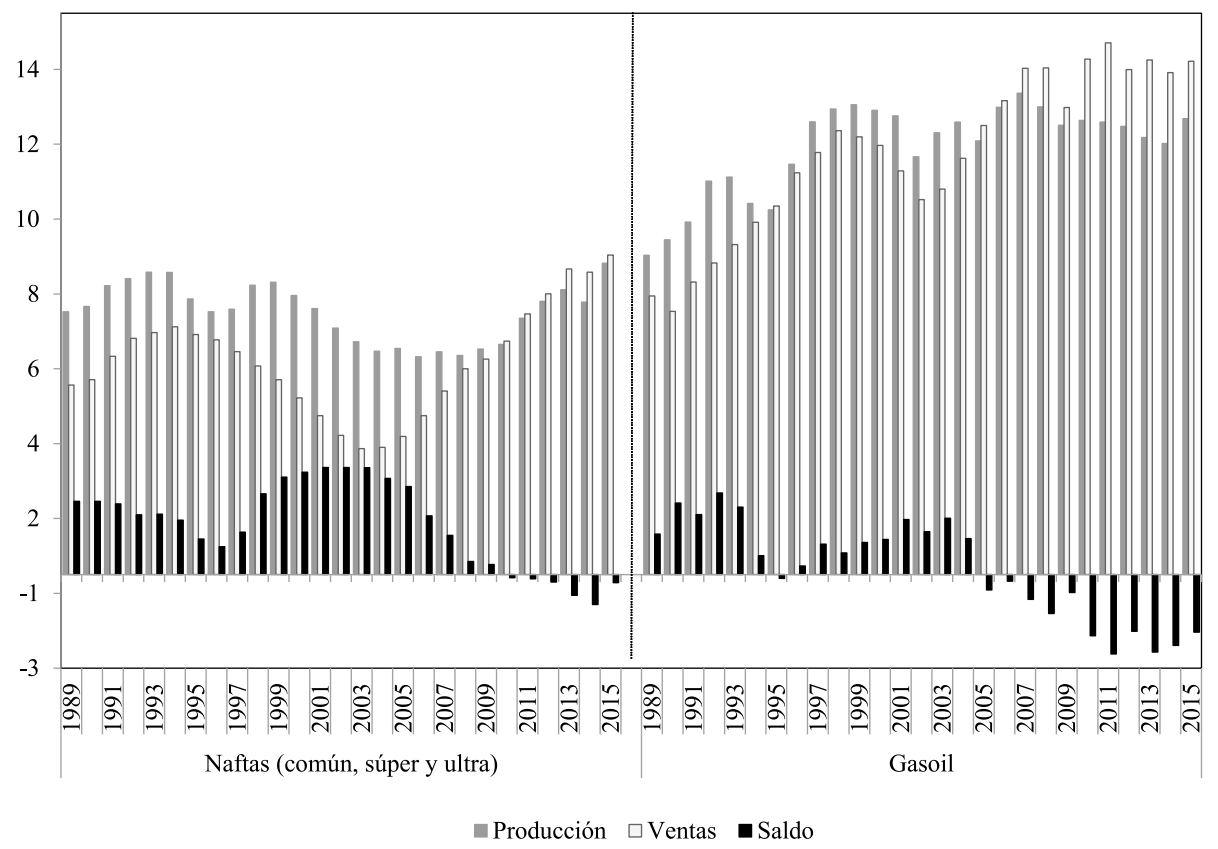

Figura 6. Evolución de la producción, de las ventas y del saldo comercial de nafta (común, súper y ultra) y gasoil, 1989-2015 (en millones de m³).

Fuente: elaboración propia con base en estadísticas del IAPG.

La evolución de los precios y las cantidades de los derivados en la posconvertibilidad

Este período histórico combinó una etapa inicial (2002-2008) de elevado TCR con precios internacionales altos con una fase intermedia (2009-2013) en la que el tipo de cambio real comenzó a apreciarse, pero el barril llegó a su máximo nivel histórico; y otra final (2014-2015) en la que el TCR se ubicó en niveles cercanos a los de la década de 1990 y los precios internacionales descendieron también a niveles de 2005 (Figura 1). En términos simples, esto implicó que en valores reales el precio del petróleo (insumo esencial para los combustibles) creciera entre 1999 y 2008 seis veces y media, por el doble efecto de tipo de cambio y precio internacional, lo que conllevó la aplicación de los derechos de exportación y de los acuerdos de precios con las refinerías.

Con base en lo que se advierte de la Figura 7, el quiebre de 2002 significó una caída en dólares del $47 \%$ de los precios de los combustibles líquidos comercializados en la plaza local. Pese a los acuerdos alcanzados, desde marzo de 2002 iniciaron una lenta pero paulatina recuperación de su cotización en moneda extranjera. Es interesante destacar 
que, como parte de la estrategia de negociación del Gobierno de Duhalde, el Estado resignó una cuota de la carga impositiva para que la recuperación de los ingresos percibidos por las refinadoras no impactara en crecimientos similares de los precios finales, abonados por el consumidor. De ahí que el valor del combustible sin impuesto se redujera en el $11.9 \%$. Luego de la crisis de 2002, la expansión de los precios percibidos por las refinerías fue superior a los finales, pagados por el consumidor. Sumado al inicio del atraso cambiario, por la estabilización cambiaria en un contexto inflacionario, esto posibilitó que hacia septiembre de 2005 los precios "sin impuestos" en moneda extranjera fueran equivalentes a los vigentes en enero de 2001, que se encontraban entre los más altos de la "larga década de 1990".

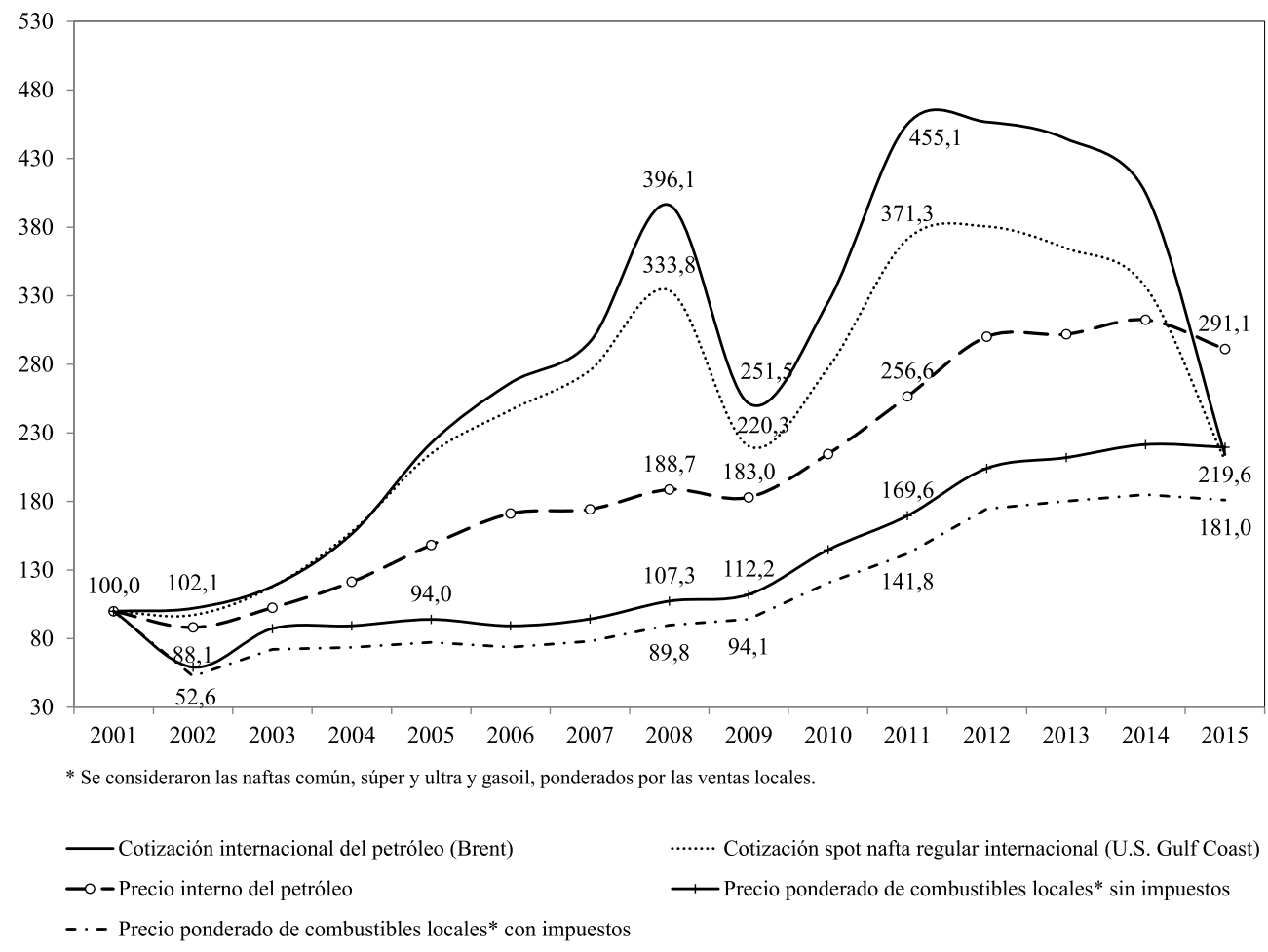

Figura 7. Evolución de los precios en dólares del petróleo internacional y local, de la nafta regular spot y de combustibles locales* $\sin$ impuestos, ene. 1997- dic. 2015 (número índice enero 2001=100).

Fuente: elaboración propia con base en estadísticas de las secretarías de energía de Argentina y de Estados Unidos.

Como fue mencionado, los derechos de exportación implementados posi- bilitaron que el precio del crudo local evolucionara por debajo del externo; sin 
embargo, producto de los acuerdos de precios, los combustibles tuvieron una dinámica de actualización inferior a la del crudo, principalmente desde 2003. En consecuencia, es posible sostener que los consumidores se vieron mayormente beneficiados en la distribución de la renta petrolera a partir de la inferior evolución de los combustibles respecto del barril de crudo. De allí que, todo parece indicar que hasta septiembre de 2008, el oligopolio refinador no pudo trasladar a los consumidores la totalidad de las alzas de precios del barril, como sí lo hacía cuando operaba con plena libertad en la década de 1990, sin por esto desconocer el importante aumento de precios que registraron los combustibles en Argentina.

Desde mediados de 2007 y principios de 2008, la brecha que separaba los precios internos del barril de crudo y de los combustibles se fue reduciendo, lo que permite advertir una recuperación de parte de la renta que había resignado el complejo refinador. Con base en la información de la Figura 7, medido en dólares corrientes, desde esos años se inició un nuevo incremento de los precios locales de los derivados, que alcanzó el 79\% hacia el 2011.

Si bien el auge de los precios del barril de petróleo marginalmente contribuyó en la explicación del fenómeno, restrin- gir el análisis a este proceso excluye otras dimensiones vinculadas a circunstancias de índole política, que parecen ser fuertes factores explicativos. En esta línea, los datos aportados por la Figura 8 permiten percibir la estrategia desplegada por el oligopolio refinador hacia el final del período analizado. Esta figura tiene la particularidad de cruzar la evolución del precio en pesos constantes de los principales combustibles líquidos ponderados por los volúmenes de venta en el mercado doméstico, con el uso de la capacidad instalada de las refinerías nacionales.

Durante el primer año posterior a la crisis de la convertibilidad, el cambio en la estructura de los precios relativos propiciado por la devaluación generó un marcado incremento de la cotización de los derivados, a pesar de los intentos del Gobierno de Duhalde por contenerlos. En este sentido, en términos reales ${ }^{16}$, en enero de 2003 alcanzaron el valor máximo ( $74 \%$ por encima de igual mes del año anterior). De ahí en adelante comenzaron a perder terreno, en la medida en que el ritmo de crecimiento de los precios de la economía fue mayor que el de los principales derivados como resultado de los distintos acuerdos de precios y sanciones mencionadas. En este sentido, entre enero de 2003 y julio de 2007, el precio real registró una pérdida del 27.4\% (al descender de 138 a 100).

16 Ante la falta de confiabilidad del índice de precios al consumidor (IPC) oficial elaborado por el INDEC, desde 2007 se consideró el IPC 9 provincias elaborado por CIFRA. Este se calcula como un promedio ponderado (por el gasto de consumo de los hogares de cada provincia) de los índices de los IPC correspondientes a nueve aglomerados nacionales (CIFRA, 2012). 
Una dinámica similar se advierte al analizar el margen de refinación (Figura 5) que presenta un deterioro notable en los años 2006/200717. En esos años, el margen absoluto se redujo el $84 \%$ y $71 \%$, respectivamente, comparado con 1992. En términos relativos, es decir, medido como porcentaje del barril de crudo, la caída es similar, porque de márgenes en torno del $80 \%$ y $220 \%$ en la década de 1990, se contrajo desde 2002 a valores mínimos en torno del
$6 \%$. Naturalmente, el impacto fue heterogéneo dependiendo de si se trataba de refinerías integradas (que también extraen petróleo) como YPF y Petrobras, en las cuales la "compra" de petróleo es un proceso contable, o de si eran refinerías sin producción de petróleo, ya que el aumento del precio del petróleo por encima de la cotización de los combustibles redujo el margen de las firmas como Shell y Esso, que adquieren en el mercado el crudo que refinan ${ }^{18}$.

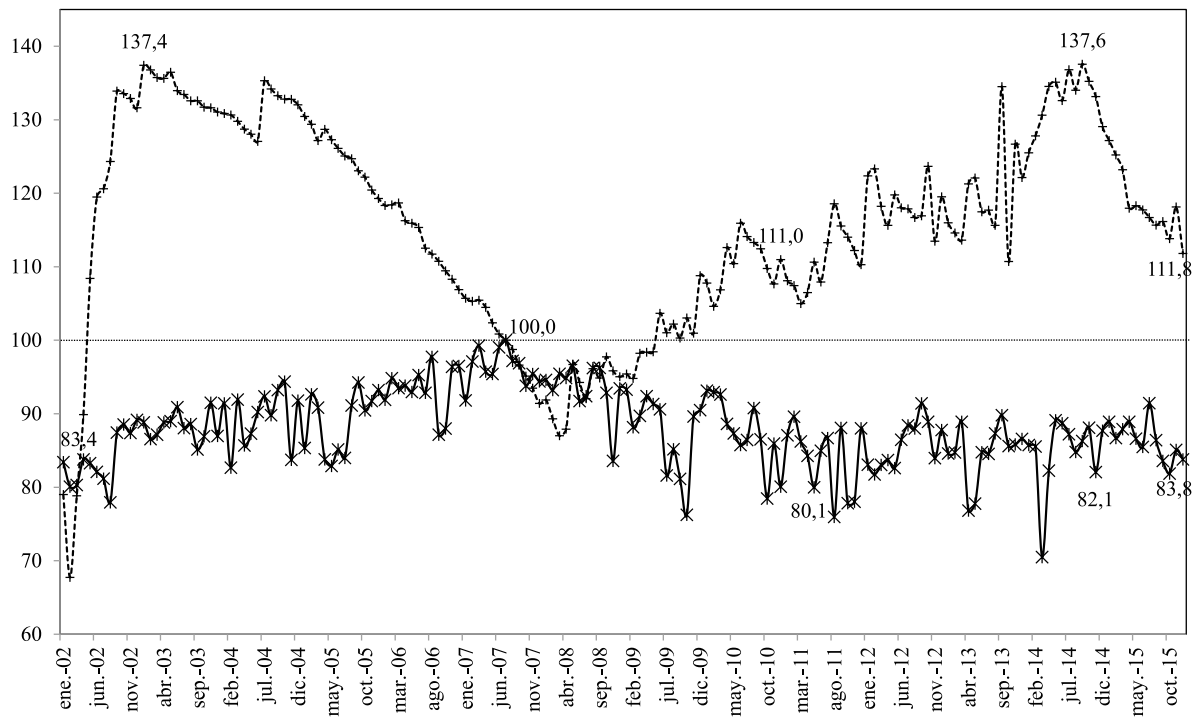

*Para el índice se consideró la comercialización de naftas común, súper y ultra y de gasoil, ponderados por las respectivas ventas de cada año.

$$
\text { --+--Precio } \rightarrow \text { Uso capac. instalada }
$$

Figura 8. Evolución mensual del precio ponderado, en valores constantes, de los principales combustibles líquidos comercializados* y del uso de la capacidad instalada de las refinerías en Argentina, 2002-2015 (número índice julio de 2007=100).

Fuente: elaboración propia con base en datos de la Secretaría de Energía, del INDEC y del IPC 9 prov. CIFRA.

17 Esta figura presenta un deterioro mayor en 2006, ya que es el año de mayor brecha entre el precio interno del crudo y el de los combustibles líquidos en dólares, a diferencia de la Figura 7, que mide el deterioro en moneda nacional. No obstante, las tendencias son similares, más allá de las discrepancias por las distintas monedas.

18 No es un dato menor que en 2011 Esso vendió sus activos a Bridas Corp., conformado en un $50 \%$ por el Grupo Bridas y la otra mitad por la firma china CNOOC, por lo que pasó a integrar la producción de petróleo a la fase de refinación. 
En este marco de pérdida relativa de la cotización de los combustibles se inserta una serie de conflictos entre el Gobierno y las refinerías Shell (principalmente) y Esso. Con el objetivo de contrarrestar este declive, y ante el incremento del valor del crudo internacional, a principios de 2005 la compañía anglo-holandesa aumentó unilateralmente el precio de sus derivados, aunque luego se sumó Esso, lo que desató un nuevo escenario de tensión con el Gobierno (Serrani, 2012). La preocupación del Poder Ejecutivo era evitar que este insumo de uso difundido impactara en el conjunto de la economía y contribuyera a acelerar el proceso inflacionario. Pero también la disputa giraba en torno de la necesidad de recomponer el poder político ante el colapso de febrero de 2001.

La decisión de estas petroleras de iniciar un proceso de incremento de los precios por fuera de los acuerdos con el Gobierno se enmarca en un contexto particular. Luego de la caída de las ventas de gasoil con el inicio de la recesión y el posterior colapso de la economía, en 2004 se superó el nivel de consumo de 2001, lo que se presentaba como el inicio de una etapa de fuerte expansión de este derivado. Además, en 2005 emergió el déficit de este combustible, por lo que obligó un aumento de las importaciones ${ }^{19}$. Este escenario le confirió mayor poder al oligopolio refinador para procurar torcer las decisiones implementadas desde el poder político.
Retomando la Figura 8, el año 2007 y principios de 2008 permiten advertir el inicio de un nuevo proceso de tensión entre el período de máximo uso de la capacidad instalada y mayor caída de los precios reales (desde 2003), que se resolvió hacia 2008 con el inicio de un ciclo de incrementos de los combustibles, los cuales se ubicaron por encima del promedio registrado por la economía. A diferencia de la etapa previa, en la cual la compañía que "comandaba" la disputa con el Gobierno era Shell, con una posición "pasiva" o a favor del Gobierno de Repsol-YPF, en la segunda etapa, esto es, entre 2008 y 2011, el conglomerado ibérico — junto con su socio local, el Grupo Petersen-, fue el que se puso al frente del proceso de recomposición de precios.

Tras los intentos fallidos por incrementar los precios por encima de la inflación, la estrategia del sector privado en su conjunto se concentró en reducir el uso de la capacidad instalada para forzar mayores importaciones. Resulta de difícil comprensión que, en un contexto en el que no existieron ampliaciones significativas en las refinerías, y en el que la demanda crecía fuertemente y se generaron faltantes que debieron ser cubiertos con importaciones, entre 2007 y 2011 el uso de la capacidad instalada descendiera, marcando una tendencia inversamente proporcional con los precios de los derivados.

19 Estudios recientes señalan que las compañías operaron con subutilización de la capacidad instalada durante esta etapa en la que se ampliaron las importaciones (Sabbatella, 2018). 
Durante estos años se profundizó la tensión entre el Gobierno y las petroleras, por los reclamos de estas últimas para alinear los precios con los internacionales y eliminar los derechos de exportación $^{20}$. En el marco del conflicto, ante el crecimiento de la demanda de energía, la política del Gobierno se orientó a incrementar las importaciones para cubrir el déficit emergente ${ }^{21}$.

Contrariamente a lo que se suponía, esta respuesta del Gobierno redundó en un debilitamiento relativo del poder político, principalmente, por dos motivos. En primer lugar, porque la mayor importación de combustibles a valores internacionales obligó al Poder Ejecutivo a cubrir, a través de diversas partidas del presupuesto nacional, los diferenciales de precios locales y externos para que no se tradujeran en mayores precios en la economía, elemento que contribuyó a afectar el superávit fiscal hasta tornarlo negativo. En segundo término, las crecientes compras externas de energía repercutieron en el balance comercial y en el de pagos, como consecuencia del importante egreso de divisas. Esta dinámica generó que en 2011 la balanza comercial energética cerrara con un déficit de 3.115 millones de dólares, que contribuyó fuertemente al proceso de restricción externa de la economía (Serrani \& Barrera, 2018; Wainer \& Arceo, 2017).

Si bien no se analizarán las causas que llevaron en 2012 a la expropiación del $51 \%$ de las acciones que Repsol tenía en YPF (Sabbatella, 2012; Schorr, Barrera, Kennedy \& Palermo, 2015), lo cierto es que la emergencia del déficit comercial luego de veinte años de superavitario fue uno de los factores. A modo de síntesis, el déficit del balance comercial de combustibles manifestó la crisis del "modelo energético" que se había instituido en la década de 1990 y que estaba impactando en la economía a partir de una fortísima salida de divisas que afianzó la restricción externa y de un incremento de los subsidios energéticos a la población, en parte, para evitar que los precios de los combustibles importados impactaran en pérdidas de competitividad de la economía y en caídas del salario real de los trabajadores (Serrani \& Barrera, 2018; Wainer \& Arceo, 2017).

Paradójicamente, la recuperación de la empresa por parte del Estado, más la sanción de un nuevo marco regulatorio (Ley 26.741 y su Decreto Reglamentario 1.277 de 2012) iniciaron una nueva etapa en la que se aceleró la recuperación de los precios de los combustibles tanto

20 Durante esos años, en los fines de semana largos había desabastecimiento de combustibles (Clarín, 2011; La Nación, 2010).

21 En esta línea, el entonces Ministerio de Planificación, expresó: “Si YPF no cumple con su obligación de proveer combustible, tal como fue la respuesta del secretario de Energía a las autolimitaciones que se puso la empresa, el Estado va a garantizar el abastecimiento del mercado. [...] Esto no es ninguna novedad, es lo que hemos hecho siempre, como lo demuestran los 9 mil millones de dólares que debimos importar en 2011 porque las petroleras, en particular YPF, no produjeron lo suficiente para abastecer al mercado interno" (La Nación, 2012). Para un desarrollo de este proceso se recomiendan Serrani y Barrera (2018). 
en moneda local como internacional (figuras 7 y 8), comandados por la YPF con mayoría estatal. Entre 2011 y 2015 , mientras que el precio internacional del crudo descendió $53 \%$, la cotización local creció $13 \%$ en dólares. Así, ante la persistente caída del crudo internacional, el Gobierno nacional estableció un "acuerdo de precios" que fijó un "barril criollo" aproximadamente en los 70 dólares cuando la cotización internacional rondaba los 50 dólares, con el argumento de que de esta manera se incentivaban inversiones en campos maduros. Este incremento de los combustibles llevó a que en la fase de refinación los precios de los combustibles en dólares crecieran un $30 \%$. En moneda local, descontando la inflación, desde mediados de 2014 se registró un descenso relativo de los combustibles, ya que la caída del precio internacional (Figura 7) quitó presión a la actualización interna en un año de elevada inflación (39\%). De allí que en la Figura 8 se advierte una caída del 10\% tomando el promedio de 2014 contra la media del año siguiente.

\section{CONCLUSIONES}

El análisis realizado permitió caracterizar el mercado de refinación de combustibles a partir de dos esquemas significativamente distintos. El primero, iniciado con las reformas neoliberales que culminaron con el estallido de la convertibilidad, en el que la existencia de dos condiciones elementales permitió dolarizar los precios de los combustibles: el tipo de cambio atrasado y los precios internacionales bajos. Se trató de una etapa en la que la morfología oligopólica del mercado le posibilitó capturar renta petrolera a las refinerías en detrimento de los consumidores, con inversiones para mejorar la calidad de los productos, pero no para ampliar la capacidad instalada, ya que era más rentable exportar el petróleo sin refinar. Un precio del crudo bajo en términos históricos y un valor de la divisa extranjera en los valores más bajos desde 1930 facilitaron altas rentabilidades en dólares para las compañías, con precios locales asequibles.

El segundo, iniciado con la devaluación de 2002, tuvo dos etapas, pero con una característica central, que fue la regulación de los precios locales por debajo de los internacionales hasta 2014. En esta primera etapa coincidieron dos procesos particulares: la devaluación del $200 \%$ en términos reales de la moneda en 2002, con el inicio del incremento de los precios internacionales desde 2003. Esta relación de precios se refleja en el índice Brent-TCR, que alcanzó niveles elevados. Mientras que en 1999 este indicador arribó a los 100 puntos, durante la década del 2000 alcanzó su máximo nivel en el 2008 con un valor de 650 puntos. La traducción de esto implica que, de haberse mantenido los precios desregulados, en moneda local la cotización del barril $\mathrm{y}$, por ende, de los derivados del petróleo (naftas, gasoil, fuel oil, lubricantes, etc.) habrían sido casi siete veces mayores en términos reales que en 1999 (es decir, 
quitando el efecto inflacionario). Tratándose de un insumo de uso difundido y del contexto macroeconómico y social de la Argentina, con fuerte caída del salario real e incremento de la pobreza y desocupación, estos datos señalan la imposibilidad de haberlos mantenido desregulados y dolarizados.

Pese a esto, no puede desconocerse que el control de los precios en un mercado altamente concentrado implicó una menor refinación de crudo por parte de las compañías privadas, como estrategia para forzar importaciones en el marco de un importante crecimiento económico y de consumo energético. La separación de los precios locales de los internacionales tuvo como resultado que las refinerías redujeran los volúmenes de destilación para forzar las importaciones en un contexto de aumento de la demanda local para tratar de converger con el "import parity". Así, la demora en la intervención en el complejo a partir de la expropiación de YPF, que permitió reducir el saldo deficitario de naftas y gasoil, contribuyó a consolidar la crisis del modelo energético y a agravar el proceso de restricción externa de la economía que se intensificó desde 2011. 


\section{REFERENCIAS}

Actualidad Energética. (1992). La privatización de YPF. Actualidad Energética, 41, $30-31$

Apud, E., Aráoz, J. C., Devoto, E., Echarte, R., Guadagni, A., Lapeña, J., ... Olocco, R. (2011). Sector energético argentino: balance de la gestión de gobierno 2003-2010. Buenos Aires: Instituto Argentino de la Energía.

Arceo, N. (2018). Las modificaciones tarifarias en la cadena del gas natural en la Argentina. Apuntes del Cenes, 37(66). https://doi.org/10.19053/01203053.v37. n66.2019.7636

Azpiazu, D. (2003). Las privatizaciones en la Argentina: diagnóstico y propuestas para una mayor competitividad y equidad social. Buenos Aires: Miño y Dávila.

Azpiazu, D. \& Schorr, M. (2001). Desempeño reciente y estructura del mercado gasifero argentino: asimetrías tarifarias, ganancias extraordinarias y concentración del capital. Buenos Aires: Flacso.

Barrera, M. (2012). Las consecuencias de la desregulación del mercado de hidrocarburos en Argentina y la privatización de YPF. Cuadernos del Cendes, 80, $101-129$.

Barrera, M. (2014). La entrega de YPF: análisis del proceso de privatización de la empresa. Buenos Aires: Cara o Ceca.

Basualdo, E. (2019). Fundamentos de economía política: los patrones de acumulación, de los clásicos al neoliberalismo del siglo XXI. Buenos Aires: Siglo XXI.

Canton, M. (2002, 22 de feb.). Se tensa más la pelea entre las petroleras y el Gobierno. Clarín.

CIFRA. (2012). Propuesta de un indicador alternativo de inflación. Buenos Aires: Cifra.

CIFRA. (2013). Informe de Coyuntura $n .^{\circ} 12$. Buenos Aires: Cifra.

Clarín. (2011, 24 de marzo). El fin de semana largo arrancó con preocupación por la falta de nafta. Clarín. 
Di Sbroiavacca, N. (2010). ¿Cuánto petróleo queda en Argentina? Proyecto Energético, 88, 6-9.

Diario de Sesiones. (1992). Diario de Sesiones de la Cámara de Diputados de la Nación. Miércoles 23 y jueves 24 de septiembre de 1992. Buenos Aires: Diario de Sesiones.

ECyT-ar. (2016). Refinerías de petróleo en Argentina. Recuperado de: http://cytar.com.ar/cyt-ar/index.php/Refinerías_de_petróleo_en_Argentina\#Refiner. C3.ADas_operativas_en_Argentina

Estenssoro, J. (1992). Transformación de Yacimientos Petrolíferos Fiscales. Gabinete Paralelo, 81-93.

Estenssoro, J. (1995, marzo). El gran juego de YPF. Estrategia según José Estenssoro. Revista Mercado, 16-19.

Esteves, J. (1998, ago.). La refinación en la Argentina. Petrotecnia, (4), 8-12.

Ferreira, P. (1998, 12 de jul.). Hay que aumentar la competencia. La posición oficial: Alberto Fiandesio, subsecretario de Combustibles. Página/12.com, Suplemento Cash.

FIEL. (1989). Los costos del Estado regulador. Buenos Aires: Manantial.

FIEL. (1999). La desregulación de la competencia y de los servicios públicos. Buenos Aires: Manantial.

Flacso. (1998). Privatizaciones en la Argentina: marcos regulatorios tarifarios y evolución de los precios relativos durante la convertibilidad. Privatización y regulación en la economía argentina n. ${ }^{\circ}$ 4. Buenos Aires: Flacso.

Gerchunoff, P. (1994). Privatización y desregulación del sector petrolero en Argentina. Serie Reformas de Políticas Públicas n. ${ }^{\circ} 24$. Santiago de Chile: Cepal. https://doi.org/10.2307/3467281

Gerchunoff, P. \& Cánovas, G. (1995). Privatizaciones en un contexto de emergencia económica. Desarrollo Económico, 34(136), 483-511.

Hancevic, P., Cont, W. \& Navajas, F. (2016). Energy Populism and Household Welfare. Energy Economics, 56, 464-474. https://doi.org/10.1016/j.eneco.2016.03.027 
Kozulj, R. (2002). Balance de la privatización de la industria petrolera en Argentina y su impacto sobre las inversiones y la competencia en los mercados minoristas de combustibles Serie Recursos Naturales e Infraestructura n. ${ }^{\circ} 46$. Santiago de Chile: Cepal.

Kozulj, R. (2005). Crisis de la industria del gas natural en Argentina. Serie Recursos Naturales e Infraestructura n. ${ }^{\circ} 88$. Santiago de Chile: Cepal.

Kozulj, R. (2012). Estrategias para el sector energético y fiscalidad: un desafío crítico. Revista Voces en el Fénix, 13(3), 85-91.

Kozulj, R. \& Bravo, V. (1993). La política de desregulación argentina: antecedentes e impactos. Buenos Aires: Centro Editor de América Latina.

La Nación. (2010, 27 de dic.). Se agravó el faltante de naftas por el fin de semana largo. La Nación. Recuperado de: https://www.lanacion.com. ar/1336705-se-agravo-el-faltante-de-naftas-por-el-fin-de-semana-largo

La Nación. (2012, feb.). De Vido aseguró que el abastecimiento de combustible "está garantizado por el Estado." La Nación. Recuperado de: http://www. lanacion.com.ar/1450465-de-vido-aseguro-que-el-abastecimiento-de-combustible-esta-garantizado-por-el-estado

Longoni, M. (2002a, 24 de feb.). Las petroleras aceptarían no aumentar las naftas. Clarín.

Longoni, M. (2002b, 25 de feb.). Sigue trabada la negociación del Gobierno con las petroleras. Clarín.

Mansilla, D. (2007). Hidrocarburos y política energética. Buenos Aires: Ediciones del CCC.

Manzanelli, P. \& Barrera, M. (2018). El sector hidrocarburífero en la última dictadura desde la cúpula empresaria argentina. Cuadernos del Cendes, 35(97), 83-109. Recuperado de: http://saber.ucv.ve/ojs/index.php/rev_cc/article/ view/15127/144814481791

Mecon. (2001a). Boletín de precios de combustibles. Buenos Aires: Mecon.

Mecon. (2001b). El proceso de privatizaciones en la Argentina desde una perspectiva del balance de pagos. Buenos: Aires Mecon. 
Ministerio de Economía. (1994). Informe sobre privatizaciones. Buenos Aires: Ministerio de Economía.

Montamat, D. (1995). Economía y petróleo. Buenos Aires: Editora PV.

Navajas, F. (2017, 18 de ene.). Exportaciones de gas: ¿Por qué tanto apuro? Cronista. Recuperado de: http://www.cronista.com/columnistas/Exportaciones-de-gas-Por-que-tanto-apuro-20170118-0023.html

Novara, N. (1997). Precios internos y de exportación de gas natural y de GLP. ¿Diferenciación o discriminación de precios en el mercado interno? Córdoba: IERAL, Fundación Mediterránea.

Palermo, H. (2017). La producción de la masculinidad en el trabajo petrolero. Buenos Aires: Biblos.

Pucciarelli, A. (comp.) (2011). Los años de Menem. La construcción del orden neoliberal. Buenos Aires: Siglo XXI.

Sabbatella, I. (2012). La política petrolera de la posconvertibilidad: de la herencia neoliberal a la expropiación de YPF. Revista Argumentos, 14, 149-180.

Sabbatella, I. (2014). Neoliberalismo y naturaleza: la "comoditización" de los hidrocarburos en Argentina (1989-2001). Revista Iberoamericana de Economía Ecológica, 22. Recuperado de: http://www.redibec.org/IVO/rev22_07.pdf

Sabbatella, I. (2018). Restricción externa durante el período posneoliberal: el caso del gasoil. Realidad Económica, 318, 59-99.

Sabbatella, I., \& Serrani, E. (2011). A 20 años de la privatización de YPF. Balance y perspectivas. Voces en el Fénix, 10, 6-15.

Schorr, M., Barrera, M., Kennedy, D. \& Palermo, H. (2015). Impacto socioeconómico de YPF desde su renacionalización: desempeño productivo los mercados laborales y el entramado de proveedores. Recuperado de: http://repositorio. cepal.org/bitstream/handle/11362/39398/S1501216_es.pdf?sequence=1

Serrani, E. (2011). Inversión y desarrollo en la paradójica transformación del mercado petrolero argentino. Papeles de Trabajo, 4, 189-213. 
Serrani, E. (2012). Estado, empresarios y acumulación privilegiada de capital. Análisis de la industria petrolera argentina (1988-2008). Buenos Aires: Universidad de Buenos Aires.

Serrani, E. \& Barrera, M. (2018). Efectos estructurales de la política energética en la economía argentina, 1989-2014. Sociedad y Economía, 34, 121-142. https://doi. org/https://doi.org/10.25100/sye.v0i34.6482

Smaal, A. (1998, agosto). La refinación en la Argentina. Petrotecnia, (4), 8-12.

U.S. Department of Justice. (2010). Horizontal Merger Guidelines. Retrieved from http://www.justice.gov/atr/public/guidelines/hmg-2010.html\#foot9

Wainer, A. \& Arceo, N. (2017). Términos de intercambio y sector energético. Su impacto sobre la restricción externa de la economía argentina. En Jornadas de Economía Crítica. Buenos Aires.

Williamson, J. (1990). What Washington Means by Policy Reform. In Latin American Adjustment: How Much has Happened? Estados Unidos: Peterson Institute for International Economics.

YPF. (1994). Memoria y balance general. Buenos Aires: YPF. 